\title{
Pharmacotherapy and adjunctive treatment for idiopathic pulmonary fibrosis (IPF)
}

\author{
Shigeki Saito ${ }^{1}$, Ala Alkhatib ${ }^{1}$, Jay K. Kolls ${ }^{1,2,3}$, Yasuhiro Kondoh ${ }^{4}$, Joseph A. Lasky ${ }^{1}$ \\ ${ }^{1}$ Department of Medicine, ${ }^{2}$ Department of Pediatrics, ${ }^{3}$ Center for Translational Research in Infection and Inflammation, Tulane University School of \\ Medicine, New Orleans, LA, USA; ${ }^{4}$ Department of Respiratory Medicine and Allergy, Tosei General Hospital, Seto, Aichi, Japan \\ Contributions: (I) Conception and design: All authors; (II) Administrative support: None; (III) Provision of study materials or patients: None; (IV) \\ Collection and assembly of data: All authors; (V) Data analysis and interpretation: All authors; (VI) Manuscript writing: All authors; (VII) Final \\ approval of manuscript: All authors. \\ Correspondence to: Joseph A. Lasky. 1430 Tulane Ave., Box 8509, New Orleans, LA 70112-2699, USA. Email: jlasky@tulane.edu.
}

\begin{abstract}
Idiopathic pulmonary fibrosis (IPF) is an advancing and fatal lung disease with increasing incidence and prevalence. Nintedanib and pirfenidone were approved by the FDA for the treatment of IPF in 2014 based on positive phase 3 trials, and both of these antifibrotic drugs are conditionally recommended in the 2015 ATS/ERS/JRS/ALAT Clinical Practice Guideline. Although an improvement over previously suggested therapies, their capacity to reduce, but not completely arrest or improve, lung function over time presents an opportunity for novel or add-on pharmacologic agents. The purpose of this review is to deliver a brief overview of the results of phase 3/4 IPF trials with pirfenidone and nintedanib, as well as highlight encouraging results of phase $1 / 2$ trials with novel therapies. Long-term studies indicate that pirfenidone and nintedanib are effective IPF treatments, with acceptable safety and tolerability. The combination of pirfenidone and nintedanib appear safe. Promising results have recently been made public for several phase 2 trials with novel targets, including the autotaxin-lysophosphatidic acid (ATX/LPA) pathway, connective tissue growth factor (CTGF), pentraxin-2, G protein-coupled receptor agonists/antagonists, $\alpha v \beta 6$ integrin, and galectin-3. Results of treatments directed at gastro-esophageal reflux in patients with IPF have also been published. Currently, monotherapy with pirfenidone or nintedanib is the mainstay of pharmacological treatment for IPF. Innovative therapies along with combinations of pharmacological agents hold great promise for the future.
\end{abstract}

Keywords: Idiopathic pulmonary fibrosis (IPF); pirfenidone; nintedanib; ATS/ERS/JRS/ALAT Clinical Practice Guideline

Submitted Feb 22, 2019. Accepted for publication Apr 12, 2019.

doi: $10.21037 /$ jtd.2019.04.62

View this article at: http://dx.doi.org/10.21037/jtd.2019.04.62

\section{FDA-approved medications: pirfenidone, nintedanib}

Over the last 10 years, several large clinical trials have been conducted to investigate the safety and efficacy of new medications for the treatment of idiopathic pulmonary fibrosis (IPF). Based on the results of those trials, the 2011 ATS/ERS/JRS/ALAT Clinical Practice Guideline for IPF was updated in 2015 (1). The updates included conditional recommendations to use two FDA-approved antifibrotic medications (pirfenidone and nintedanib). Since the 2015
Guideline, new data from phase 4 studies employing these antifibrotic drugs have become available. Tables 1,2 highlight features of phase 3 and 4 clinical trials respectively for nintedanib and pirfenidone.

\section{Pirfenidone}

Pirfenidone is an antifibrotic and anti-inflammatory medication that decreases both fibroblast proliferation and the accumulation of collagen (8). In 2010, a randomized 
Table 1 Key aspects of the phase 3 clinical trials evaluating pirfenidone or nintedanib in IPF (all are multicenter, double-blind, randomized, placebo-controlled trials)

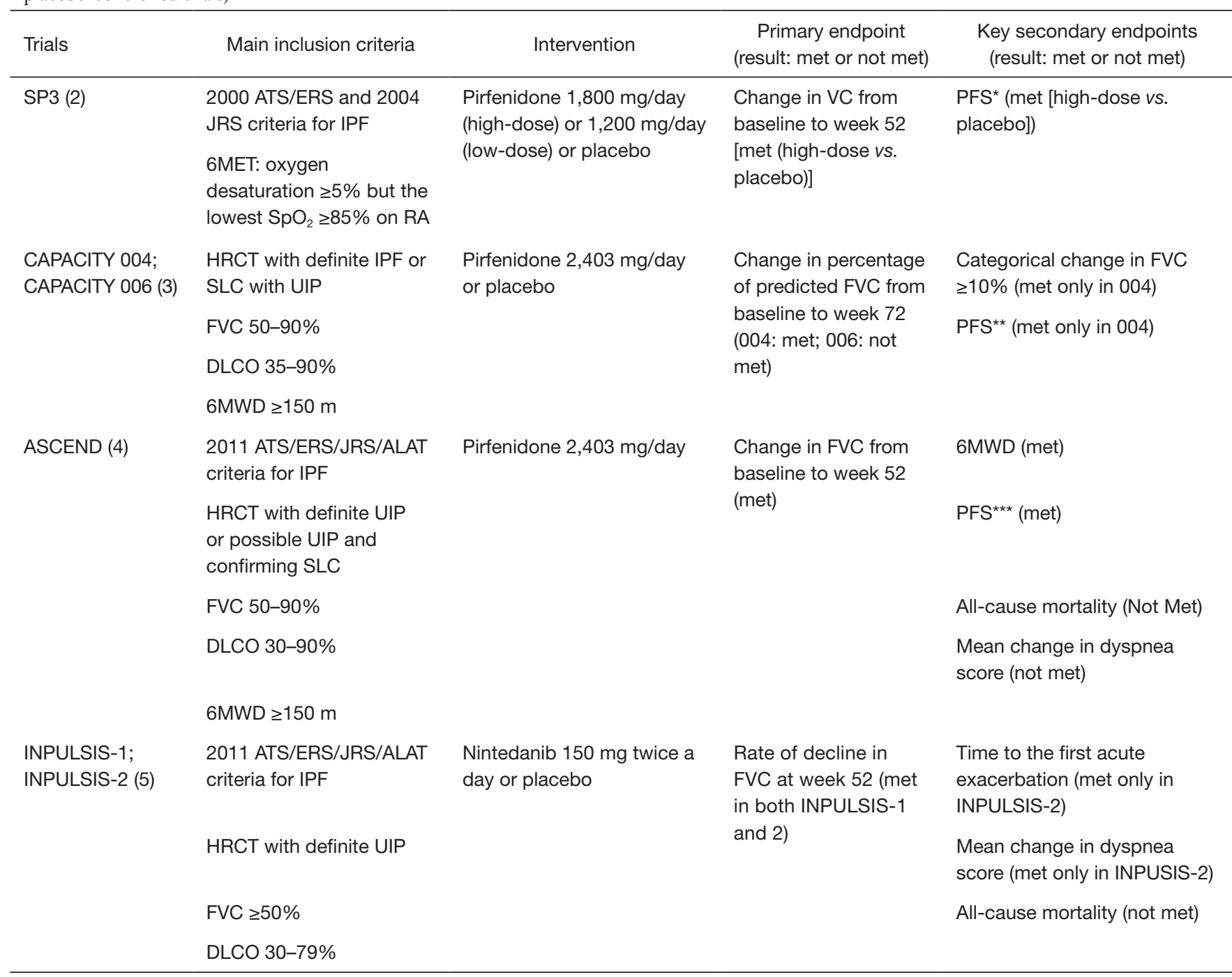

*, the progression of disease was defined by death and/or $\geq 10 \%$ decline in VC from baseline; ${ }^{* *}$, the progression of disease defined as time to $\geq 10 \%$ decline in FVC, $\geq 15 \%$ decline DLCO or death; ${ }^{* *}$, PFS defined as the time to $\geq 10 \%$ decline in FVC from baseline, a decrease of $50 \mathrm{~m}$ or more in 6MWD, or death. IPF, idiopathic pulmonary fibrosis; DLCO, diffusing capacity of the lung for carbon monoxide; $\mathrm{FEV}_{1}$, forced expiratory volume in 1 second; FVC, forced vital capacity; HRCT, high-resolution computed tomography; PFS, progression-free survival; RA, room air; SLB, surgical lung biopsy; UIP, usual interstitial pneumonia; 6MET, 6-min steady-state exercise test; 6MWD, 6-min walk test distance.

phase 3 clinical trial was published with results that pirfenidone may decrease the rate of decline in forced vital capacity (FVC) in Japanese patients with IPF (2). In 2011, the CAPACITY trials reported the results of two independent studies (CAPACITY 004 and 006) comparing high dose pirfenidone $(2,403 \mathrm{mg} / \mathrm{d})$ with placebo (3). CAPACITY 004 showed that pirfenidone significantly diminished the falloff in FVC over a 72-week treatment period, whereas CAPACITY 006 did not. Of note, the placebo group in CAPACITY 006 somehow experienced a comparatively limited decline in the FVC, thus potentially mitigating the ability to observe a statistically significant effect in the treatment arm.

The ASCEND trial was a randomized, double-blind, placebo trial comparing pirfenidone with placebo in IPF patients with an FVC between $50 \%$ and $90 \%$ and 
Table 2 Key aspects of the phase 4 clinical trials evaluating pirfenidone or nintedanib in IPF

\begin{tabular}{|c|c|c|c|c|}
\hline Trials & Study design & $\begin{array}{l}\text { Main inclusion } \\
\text { criteria }\end{array}$ & Intervention & Results \\
\hline \multirow[t]{4}{*}{ RECAP (6) } & \multirow{4}{*}{$\begin{array}{l}\text { Open-label, } \\
\text { multicenter, } \\
\text { single-arm, } \\
\text { rollover study }\end{array}$} & \multirow{4}{*}{$\begin{array}{l}\text { Patients with IPF } \\
\text { who completed } \\
\text { CAPACITY } \\
\text { 004/006 or } \\
\text { ASCEND }\end{array}$} & \multirow[t]{4}{*}{ Pirfenidone 2,403 mg/day } & Median exposure to pirfenidone was 88 weeks \\
\hline & & & & $\begin{array}{l}\text { The rate of treatment-emergent adverse event } \\
\text { (TEAE) was } 701.9 \text { per } 100 \mathrm{PEY}\end{array}$ \\
\hline & & & & The serious TEAE rate was 53.5 per 100 PEY \\
\hline & & & & $\begin{array}{l}\text { The treatment discontinuation rate due to a } \\
\text { TEAE was } 17.9 \text { per } 100 \mathrm{PEY}\end{array}$ \\
\hline \multirow[t]{2}{*}{ INPULSIS-ON (7) } & \multirow{2}{*}{$\begin{array}{l}\text { Open-label, } \\
\text { multicenter } \\
\text { study }\end{array}$} & \multirow{2}{*}{$\begin{array}{l}\text { Patients with IPF } \\
\text { who completed } \\
\text { INPULSIS }\end{array}$} & \multirow{2}{*}{$\begin{array}{l}\text { Nintedanib } 150 \text { or } 100 \mathrm{mg} \\
\text { twice a day }\end{array}$} & Median exposure to nintedanib was 31.5 months \\
\hline & & & & $\begin{array}{l}\text { The safety profile was consistent with that } \\
\text { observed in INPULSIS }\end{array}$ \\
\hline
\end{tabular}

IPF, idiopathic pulmonary fibrosis.

carbon monoxide diffusing capacity (DLCO) between $30 \%$ and $90 \%$ of the predicted value (4). In this trial, pirfenidone significantly reduced the rate of decline in FVC over a 1-year follow-up period by approximately $50 \%$ (the primary endpoint), and increased the 6-minute walk distance (6MWD) and progression-free survival. RECAP, an open-label extension study of the CAPACITY and ASCEND, showed a similar side effects profile to those reported in CAPACITY and ASCEND, thus demonstrating a favorable safety profile (6). Realworld safety results from 1,009 patients in prospective, observational PASSPORT study were also consistent with the known pirfenidone safety profile (9). Pirfenidone should be taken three times daily with food at a target dose of $801 \mathrm{mg}$ that is generally achieved over 14 days (267 $\mathrm{mg}$ three times daily for 1 week, $534 \mathrm{mg}$ three times daily for 1 week, and then $801 \mathrm{mg}$ three times daily thereafter) (10). Liver enzymes should be measured at baseline and followed monthly for 6 months and every 3 months thereafter. Pirfenidone should not be used in patients with Child-Pugh class C liver impairment or patients requiring dialysis.

Reported side effects include rash, photosensitivity, and gastrointestinal discomfort. Patients should be advised to use sunblock and limit or avoid sun exposure. Taking pirfenidone with meals is also recommended because this may control gastrointestinal symptoms. Antacids and antiemetics can be prescribed if the patient continues to have gastrointestinal symptoms, though omeprazole should be avoided because it may modulate pirfenidone levels $(11,12)$. In the event that side effect symptoms and/or hepatotoxicity (transaminitis) arise, the dose can be decreased, or temporarily stopped and reintroduced a few weeks later using a slower dose titration (11). Pirfenidone is mainly metabolized by cytochrome P450 1A2 (CYP1A2) enzymes, and therefore should be avoided or used with extreme caution if the patient is using concomitantly other CYP1A2 inhibitors (e.g., fluvoxamine, ciprofloxacin) or inducers [e.g., tobacco, omeprazole, rifampicin (weak)] (13).

\section{Nintedanib}

Nintedanib is a small molecule inhibitor of receptor tyrosine kinases, including platelet-derived growth factor (PDGF) receptor, fibroblast growth factor (FGF) receptor, and vascular endothelial growth factor (VEGF) receptor (14). Nintedanib was evaluated in a phase 2 trial (TOMORROW), which was followed by duplicate 52 -week, randomized, double-blind, phase 3 trials (INPULSIS-1 and -2). The inclusion criteria of the INPUSIS trials was similar to that of the ASCEND trial, 
except that INPUSIS allowed for inclusion of patients with possible usual interstitial pneumonia (UIP) based on high-resolution computed tomography (HRCT) when a surgical biopsy was not available (roughly $20 \%$ of enrolled patients) (5). In both INPULSIS-1 and -2 , nintedanib led to a significant reduction in the rate of decline in FVC over 1-year of follow-up (the primary outcome), but did not demonstrate statistically significant decrease in mortality as it was underpowered to do so. Nintedanib also reduced the time to the first investigator-reported acute exacerbation (AE) in INPULSIS-2, but not in INPULSIS-1. In the pooled analysis, nintedanib reduced the time to the first adjudicated $\mathrm{AE}$.

An open-label extension of the INPULSIS trials (INPULSIS-ON), demonstrated that long-term use of nintedanib bears a manageable safety and tolerability profile and slows disease progression in patients with IPF (7). Nintedanib was associated with a very slight (but not statistically significant) increase in myocardial infarction in INPULSIS, but this was not appreciated in INPULSIS-ON.

The recommended dose of nintedanib is $150 \mathrm{mg}$ orally twice a day, and liver enzymes should be monitored monthly for the initial 3 months then every 3 months thereafter. Nintedanib should be avoided in patients with moderate or severe liver impairment (Child-Pugh class B or C) (15). Reported side effects include diarrhea and nausea, which can often be effectively managed with antidiarrheal medications or antiemetics (12). In the event that side effect symptoms and/or hepatotoxicity arise, the dose can be decreased, or temporarily stopped and reintroduced with close monitoring in a few weeks (13). Nintedanib is a substrate of $\mathrm{P}$-glycoprotein $(\mathrm{P}-\mathrm{gp})$ and CYP3A4. Coadministration with oral doses of a P-gp and CYP3A4 inhibitor (e.g., ketoconazole, erythromycin) with nintedanib may increase exposure to nintedanib. Thus, patients should be monitored closely for tolerability of nintedanib when such drugs are considered. Coadministration with oral doses of a P-gp and CYP3A4 inducer (e.g., rifampicin, carbamazepine, phenytoin, St. John's wort) may decrease exposure to nintedanib.

\section{Which to choose, pirfenidone, or nintedanib?}

Differences in mortality between the placebo and active drug groups in the ASCEND and INPULSIS trials was not statistically different, perhaps because they were underpowered. However, subsequent publications of meta- analysis from multiple trials suggest that both pirfenidone and nintedanib lowered mortality compared to placebo $(15,16)$. Additionally, subsequent post-hoc studies have demonstrated that both medications have been effective in reducing lung volume loss, regardless of the initial reported FVC and DLCO $(15,16)$.

Choosing one antifibrotic over the other can be difficult given the absence of head-to-head randomized trials, and so the decision should be based on what is more suitable for the individual patient. Pirfenidone over nintedanib may be considered in patients at increased risk for bleeding (including patients who are on fulldose anticoagulation or dual antiplatelet therapy), since nintedanib may increase the risk of bleeding by inhibiting VEGF receptor signal transduction (14). However, it should be noted that the slight increase in reported bleeding in clinical trials for patients taking nintedanib compared to placebo were minor events, such as bruising or epistaxis. Nintedanib might be selected over pirfenidone based on a patient's inability to avoid sun exposure, or preexisting dermatologic condition, since photosensitivity and rash were increased in patients taking pirfenidone in the phase 3 trials.

\section{Combining pirfenidone and nintedanib}

In 2015, a randomized phase 2 trial in Japanese patients with IPF demonstrated that nintedanib had an acceptable safety profile when added to ongoing pirfenidone therapy (17). Later in 2017, Vancheri and colleagues investigated the safety of combining pirfenidone and nintedanib in treating IPF (18). In this trial, IPF patients who completed 4 to 5 weeks of nintedanib with no interruption or dose reduction were randomized to receive nintedanib with add-on pirfenidone or nintedanib alone in an open-label study for 12 weeks. Nintedanib with addon pirfenidone had a manageable safety and tolerability profile in patients with IPF, and was in keeping with the adverse event profiles of each drug. The safety and tolerability of pirfenidone with add-on nintedanib were also demonstrated in a single-arm, open-label, 24-week study (19). Another open-label trial published in 2019 indicates that co-administration of nintedanib and pirfenidone had no relevant effect on their pharmacokinetic (PK) drug-drug interaction (20). The results of these trials provides evidence that the combination of pirfenidone and nintedanib appears safe which opens the door for other future randomized clinical trials to evaluate whether the 
combination enhances effectiveness. As such, we do not currently employ pirfenidone and nintedanib together to treat IPF.

\section{Novel therapies with encouraging results in phase 2 trials (summarized in Table 3)}

\section{Autotaxin-lysophosphatidic acid (LPA) pathway inbibitors}

LPA, which is primarily converted from lysophosphatidylcholine by autotaxin, has been implicated in various fibrogenic pathways in different tissues, including the lung (24). Targeting the autotaxin-LPA pathway by inhibiting autotaxin or LPA receptors is being actively researched in various fibrotic diseases, including pulmonary fibrosis, skin fibrosis (scleroderma), and liver fibrosis $(25-27)$.

\section{GLPG1690 (autotaxin inhibitor)}

The FLORA study (ClinicalTrials.gov number: NCT02738801) was a randomized, double-blind, parallel-group, placebo-controlled phase $2 \mathrm{a}$ trial which explored the safety and efficacy of GLPG1690 (an autotaxin inhibitor) in IPF patients who were not taking pirfenidone or nintedanib (21). In this trial, GLPG1690 was well tolerated over the 12 -week treatment period. FVC decreased in the placebo group but remained similar to, or greater than, baseline values in the GLPG1690 treatment group. These data appear encouraging to move forward with further trials employing GLPG1690 as a treatment for IPF. Two phase 3 parallel studies [ISABELA1 (NCT03711162) and ISABELA2 (NCT03711162)], which allow concurrent treatment with pirfenidone or nintedanib, have started enrollment.

\section{BMS-986020 [LPA receptor 1 (LPA1) antagonist]}

In a phase 2, multiple-dose, three-group, parallel-arm, randomized, double-blind, placebo-controlled trial (NCT01766817) that gauged the efficacy and safety of BMS-986020 $600 \mathrm{mg}$ daily or twice a day for 26 weeks in patients with IPF (who were not on pirfenidone or nintedanib), patients treated with BMS-986020 twice a day exhibited a significantly more gradual rate of decline in FVC vs. placebo (28). However, dose-related elevations in hepatic enzymes were observed in both BMS-986020 treatment groups. The study was halted early because of three cases of cholecystitis that were deemed related to BMS-986020. The authors speculated that these adverse events were not likely related to LPA1 antagonism, but were instead off target compound specific occurrences, based on preclinical studies comparing BMS-986020 with a structurally distinct LPA1 antagonist (BMS-986234). They concluded that additional research with LPA1 antagonists is warranted.

\section{Anti-connective tissue growth factor (CTGF) antibody}

\section{Pamrevlumab (FG-3019, anti-CTGF antibody)}

CTGF, a pro-fibrotic matricellular protein, has been implicated in various fibrogenic pathways in different organs, including the lung (29,30). Pamrevlumab (FG-3019) is a human monoclonal antibody against CTGF, and has been evaluated in patients with IPF. A phase 2, prospective, open-label trial of pamrevlumab (NCT01262001) in 89 people with IPF demonstrated acceptable safety and tolerability (31). The results of this trial also suggested that pamrevlumab may have stabilized or improved FVC and lung fibrosis as assessed by quantitative HRCT (qHRCT) in about one third of patients. Based on these findings, a phase $2 \mathrm{~b}$ PRAISE trial (a randomized, double-blind, placebo-controlled trial designed to investigate the safety and efficacy of pamrevlumab in patients with IPF with mild to moderate disease; NCT01890265) was conducted, and some of the results were presented at ERS 2017 conference and ATS 2018 conference. In comparison to placebo, pamrevlumab treatment significantly slowed the decline in FVC and had a favorable impact on qHRCT (32). Full publication of the results of this trial are awaited.

\section{Pentraxin-2}

\section{PRM-151 (recombinant human pentraxin-2)}

Pentraxin-2 [also known as serum amyloid P (SAP)] regulates several aspects of the innate immune system. Pentraxin-2 blocks bleomycin-induced pulmonary fibrosis in mice, likely by inhibiting the differentiation of fibrocytes (monocytederived fibroblast-like cells), promoting the formation of immuno-regulatory macrophages, and inhibiting neutrophil adhesion to extracellular matrix proteins $(33,34)$.

In a phase 2, randomized, double-blind, placebocontrolled trial (NCT02550873) involving 117 patients with IPF, treatment with intravenous PRM-151 every 4 weeks for 24 weeks was well tolerated, and resulted in a change in FVC percentage of predicted value of $-2.5 \%$ compared with $-4.8 \%$ with placebo, a difference that was statistically significant (22). This effect was independent of 
Table 3 Summary of recent phase 2 trials on novel agents for IPF treatment that suggested safety and efficacy

\begin{tabular}{|c|c|c|c|c|}
\hline $\begin{array}{l}\text { Trial acronym /clinicaltrials. } \\
\text { gov identifier }\end{array}$ & Study medication & Study design & Main findings & Status/publication \\
\hline FLORA/NCT02738801 & $\begin{array}{l}\text { GLPG1690 } \\
\text { (autotaxin inhibitor) }\end{array}$ & $\begin{array}{l}\text { 12-week, } \\
\text { randomized, } \\
\text { double-blind, } \\
\text { placebo-controlled } \\
\text { (no pirfenidone or } \\
\text { nintedanib) }\end{array}$ & $\begin{array}{l}\text { FVC decreased in the } \\
\text { placebo group but } \\
\text { remained similar to or } \\
\text { greater than baseline } \\
\text { values in the GLPG1690 } \\
\text { treatment group }\end{array}$ & $\begin{array}{l}\text { Published in Lancet Respir Med } \\
\text { (21) } \\
\text { Two phase } 3 \text { parallel studies } \\
\text { (ISABELA1\&2) are actively } \\
\text { recruiting }\end{array}$ \\
\hline PRAISE/NCT01890265 & $\begin{array}{l}\text { Pamrevlumab (FG- } \\
\text { 3019, anti-CTGF } \\
\text { antibody) }\end{array}$ & $\begin{array}{l}\text { 48-week, } \\
\text { randomized, } \\
\text { double-blind, } \\
\text { placebo-controlled }\end{array}$ & $\begin{array}{l}\text { Pamrevlumab treatment } \\
\text { significantly reduced the } \\
\text { rate of fibrosis progression } \\
\text { measured by change } \\
\text { in FVC and } \mathrm{qHRCT} \text {, in } \\
\text { comparison to placebo }\end{array}$ & $\begin{array}{l}\text { Presented at ERS } 2017 \text { and } \\
\text { ATS } 2018 \\
\text { A phase } 3 \text { trial is planned }\end{array}$ \\
\hline NCT02538536 & $\begin{array}{l}\text { PBI-4050 (a dual } \\
\text { modulator of } \\
\text { GPR40 and GPR84) }\end{array}$ & $\begin{array}{l}\text { 12-week, single- } \\
\text { arm, open-label } \\
\text { (pirfenidone or } \\
\text { nintedanib was } \\
\text { allowed) }\end{array}$ & $\begin{array}{l}\text { FVC was stable in patients } \\
\text { on } \mathrm{PBI}-4050 \text { alone and } \\
\mathrm{PBI}-4050+\text { nintedanib, } \\
\text { whereas FVC dropped } \\
\text { significantly in patients on } \\
\mathrm{PBI}-4050 \text { + pirfenidone }\end{array}$ & Published in Eur Respir J (23) \\
\hline NCT02257177 & $\begin{array}{l}\text { TD139 (inhaled anti- } \\
\text { galectin } 3 \text { small } \\
\text { molecule) }\end{array}$ & $\begin{array}{l}\text { 14-day, open-label, } \\
\text { dose escalating } \\
\text { trial (phase 2a) }\end{array}$ & $\begin{array}{l}\text { The drug was well } \\
\text { tolerated } \\
\text { Target suppression was } \\
\text { observed as measured by } \\
\text { galectin } 3 \text { expression on } \\
\text { BAL macrophages }\end{array}$ & $\begin{array}{l}\text { Phase } 2 b \text { study is actively } \\
\text { recruiting }\end{array}$ \\
\hline
\end{tabular}

IPF, idiopathic pulmonary fibrosis; qHRCT, quantitative high-resolution computed tomography; FVC, forced vital capacity; CTGF, connective tissue growth factor; PK, pharmacokinetic; BAL, bronchoalveolar lavage. 
concurrent IPF therapy (i.e., pirfenidone or nintedanib, or none). These preliminary findings suggest that recombinant human pentraxin-2 may reduce regression in lung function in patients with IPF. A phase 3 trial is planned to confirm these findings.

\section{GPR40 agonist/GPR84 antagonist}

\section{PBI-4050 (a dual modulator of GPR40 and GPR84)}

PBI-4050 is a medium-chain fatty acid synthetic analogue with agonist and antagonist ligand affinity towards two G-protein coupled receptors, GPR40 (broadly expressed on various kinds of cells) and GPR84 (highly expressed on immune cells), respectively. PBI-4050 inhibits bleomycininduced pulmonary fibrosis in mice, via its effects on several cell types including macrophages, fibroblasts and epithelial cells (35). In a 12-week, phase 2, single-arm, open-label study (NCT02538536), PBI-4050 was well tolerated when administered alone or in combination with nintedanib or pirfenidone (23). PK profiles for PBI-4050 were reduced with pirfenidone, suggesting a drug-drug interaction, but not in combination with nintedanib. The FVC was stable over time in patients treated with PBI-4050 alone and PBI-4050 + nintedanib, whereas the FVC exhibited a significant decline in patients on PBI-4050 + pirfenidone. A phase 3 trial is planned to study the efficacy of PBI- 4050 alone or in combination with nintedanib.

\section{Anti- avß6 integrin antibody}

BG00011 (anti- $\alpha v \beta 6$ integrin monoclonal antibody) $\alpha v \beta 6$ integrin is upregulated on alveolar epithelial cells in IPF patients and drives local activation of TGF- $\beta$ and thereby fibrogenesis $(36,37)$. A phase 2 a randomized, placebo controlled, trial was conducted in IPF patients to evaluate safety, tolerability and exposure response of TGF- $\beta$ suppression (NCT01371305). The results have not been published, but were presented at ATS 2018 conference. Subcutaneous weekly administration of BG00011 was safe and well tolerated, except for the highest dose ( $3 \mathrm{mg} / \mathrm{kg}$ subcutaneous weekly). The study also demonstrated a decrease in active TGF- $\beta$ signaling as evidenced by dose dependent reductions in SMAD2 phosphorylation and TGF- $\beta$ target gene expression in bronchoalveolar lavage (BAL) cells in patients receiving BG00011. A 52-week phase 2b study using BG00011 in patients with IPF is actively recruiting participants (SPIRIT study, NCT03573505).

\section{Galectin-3 inbibitor}

\section{TD139 (an inhaled anti-galectin 3 small molecule)}

Galectin-3 is a pro-fibrotic $\beta$-galactoside binding lectin that has enhanced expression in fibrotic lung and macrophages from IPF patients. It has been shown to promote fibrosis through modifying the activity of TGF- $\beta$ (38). The result of a phase 2a study with TD139 (an inhaled antigalectin 3 small molecule) in IPF was presented at ATS 2017 conference. TD139 was well tolerated, and target suppression was substantiated as measured by galectin-3 expression on BAL macrophages. A phase $2 \mathrm{~b}$ study in IPF patients has been launched.

\section{Inbaled interferon- $\gamma(I F N-\gamma)$}

IFN- $\gamma$ is a cytokine that can stimulate macrophage function and inhibit fibrotic pathways (39). INSPIRE, a large phase 3 trial, failed to demonstrate the efficacy of subcutaneous IFN- $\gamma 1 \mathrm{~b}$ therapy on IPF patient survival (40). One of the reasons for the failure might have been the mode of delivery. It has been speculated that inhalational IFN- $\gamma$ therapy might be more effective than systemic IFN- $\gamma$ therapy in activating alveolar macrophages (41).

In an 80-week phase 2 trial involving 10 IPF patients (NCT00563212), inhaled IFN- $\gamma$ aerosol (100 $\mu \mathrm{g} 3$ times/ week) was well tolerated. IFN- $\gamma$ was significantly increased in BAL fluid, and some profibrotic cytokines (FGP-2, Flt3 ligand, IL-5) were markedly lowered, although IP-10 (a bona fide target gene of IFN- $\gamma$ ) was unchanged (42). DLCO was significantly improved following inhaled IFN- $\gamma$ therapy, although change in FVC was not statistically significant (43).

The authors concluded that these results warrant the continued evaluation of inhaled IFN- $\gamma$.

\section{Rituximab}

Investigators have proposed that autoantibodies may be involved in IPF pathobiology, particularly in regard to rapid clinical declines referred to as AEs (44). To address this concept, Donahoe et al. conducted a pilot trial (NCT01266317) in which therapeutic plasma exchanges (TPE) and rituximab were used to treat 11 critically-ill AE-IPF patients. The study population was compared to 20 historical control AE-IPF patients treated with conventional glucocorticoid therapy. Nine of the 11 patients demonstrated improvements of gas exchange when treated with TPE and rituximab, compared to only one 
patient in the historical control population. What is more, trial subjects had a 1 -year survival of $46 \%$, whereas no patients were alive at 1 year in the historical control group. TPE was also associated with a reduction in anti-HEp-2 autoantibodies in patients who responded to treatment, and TPE and rituximab did not appear to cause serious adverse events. The authors concluded that autoantibody-targeted therapies might benefit AE-IPF patients (44).

\section{Anti-acid therapies}

Gastroesophageal reflux (GERD) is a common comorbidity in IPF (45), though it is difficult to know whether it is cause or effect. The fibrotic lung can in theory contribute to reflux by reducing lung volume, thus elevating the hemidiaphragm, and lead to higher negative pressures in the thoracic cavity to expand the stiff lung. In addition, IPF is a disease that begins in the periphery of the lobule. The consideration that lung injury due to inhalation tends to at least have an airway centric component, speaks against a causal effect of GERD for IPF. Nevertheless, intuitively aspiration on top of fibrosis would be expected to be unfavorable. An early manuscript by Lee $e t$ al. observed that anti-acid therapy in IPF patients was associated with longer survival (46). In addition, a retrospective review of patients enrolled in IPF clinical trials indicated that anti-acid therapy was associated with a diminished rate of decline in FVC over time in patients with IPF (47). Thus, the 2015 IPF Guideline made a weak recommendation for anti-acid therapy based on data available at the time (1). Subsequent studies questioned whether the recommendation for antiacid therapy in patients with IPF is valid. A retrospective analysis of data derived from another set of clinical trials did not reveal improvement in outcomes when anti-acid therapy was employed; instead, it found that pneumonia was more common in IPF patients with moderate restriction when anti-acid therapy was used $(48,49)$.

Inasmuch as anti-acid therapy would not stop aspiration of other possibly noxious components in refluxed material, anti-reflux surgery has been investigated. WRAP-IPF study is a phase 2 trial in which 29 patients with a DeMeester score (a composite score of the acid exposure during a prolonged ambulatory $\mathrm{pH}$ monitoring) $\geq 14.7$ were randomized to laparoscopic fundoplication and compared to 29 controls. Although fundoplication appeared to be safe and there were favorable trends in $\mathrm{AE}$, respiratory-related hospitalization, death and loss of lung function over time in favor of those that received fundoplication, these findings did not reach statistical significance (50). It is possible that the WRAP-IPF study may have been underpowered. Of note, although the study was multi-centered, the majority of patients were enrolled from a single site.

Taking into account three meta-analyses to date addressing anti-acid therapy in IPF are all inconclusive (51-53), our current bias is to employ anti-acid therapy along with other anti-reflux measures when cough is a vexing symptom. We also consider manometry and 24-hour $\mathrm{pH}$ monitoring in selected patients when the history or exam suggests aspiration may be occurring or when loss of lung volume is higher than expected while on antifibrotic therapy. If testing indicates significant reflux, we discuss the option of fundoplication with our patients.

\section{Antibiotic therapy}

Recent studies have highlighted significant differences between the microbiota in IPF subjects and healthy controls, and suggested that changes in the overall bacterial burden are related to IPF disease progression (54). A multicenter randomized placebo-controlled doubleblind parallel-group study employed co-trimoxazole for 12 months in 181 patients with fibrotic idiopathic interstitial pneumonia (approximately $90 \%$ of them diagnosed with definite/probable IPF, and the remaining diagnosed with fibrotic nonspecific interstitial pneumonia). Treatment with co-trimoxazole was associated with an improved quality of life, though there was no discernable change in lung function (55). Analysis of patients adhering to study medication or withdrawing from the trial prior to death suggested that there was a significant reduction in deaths in study subjects treated with co-trimoxazole. This should be interpreted with caution, since this could be due to increased mortality in those withdrawing from the drug because of side effects, or the higher withdrawal rate in the active group could be a marker of the disease severity. However, the authors state that those possibilities are less likely because a disproportionate withdrawal of patients in the treatment arm immediately prior to death was not observed. They also stated that the treatment effect of cotrimoxazole did not seem to be limited to patients taking immunosuppressive therapy in the subgroup analysis, and inferred that co-trimoxazole may improve survival in people with IPF by reducing respiratory infections.

Two ongoing trials, CleanUP-IPF and EME-TIPAC, are investigating the use of co-trimoxazole or doxycycline in carefully characterized patients with IPF (56). 


\section{Therapies for pulmonary hypertension (PH) associated with IPF}

The 2015 IPF Guideline recommended against the use of pulmonary arterial hypertension (PAH)-specific medications [e.g., phosphodiesterase 5 inhibitor (PDE5), endothelin receptor antagonist, prostanoid] for $\mathrm{PH}$ associated with IPF (1). Since then, there has been no new study supporting the use of those medications for PH associated with IPF.

Recently, the safety and efficacy of sildenafil in patients with IPF was tested in the INSTAGE trial, in which sildenafil plus nintedanib was tested against nintedanib alone (57). INSTAGE was designed based on a subgroup analysis of the STEP-IPF trial (58), which suggested that sildenafil, in IPF patients with a very low DLCO, may aid in oxygenation, gas exchange as measured by DLCO, symptoms, and quality of life (59).

In INSTAGE, 274 patients with IPF and DLCO $\leq 35 \%$ were randomized to nintedanib + sildenafil or nintedanib + placebo for 24 weeks. Randomization was stratified according to the presence of right ventricular systolic dysfunction, right ventricular hypertrophy, right ventricular dilatation, paradoxical septum motion, or right atrium enlargement. There was a positive trend, but no significant difference with the inclusion of sildenafil in the primary endpoint, which was the adjusted mean change from baseline in the St. George's Respiratory Questionnaire (SGRQ). Moreover, the addition of sildenafil did not statistically impact on dyspnea as measured with the University of California San Diego (UCSD) Shortness of Breath Questionnaire. No new safety signals were observed with the drug combination. Interestingly, as shown in the manuscript supplement, patients treated with nintedanib + sildenafil had a lower risk of arriving at an absolute decline in the $\mathrm{FVC}$ of $\geq 5 \%$ or death in comparison to patients treated with nintedanib + placebo. The authors stated "given the likely fragility of this finding, this observation cannot be considered to be clinically directive". It remains possible that the INSTAGE trial was underpowered or its duration was too brief. An ongoing 52-week phase 2b randomized, double-blind, placebo-controlled trial evaluating the safety and efficacy of sildenafil in IPF patients on pirfenidone will hopefully provide further insights (60).

At this point we cannot recommend the use of PDE5 inhibitors in patients with IPF or PH associated with IPF. It should be kept in mind that RISE-IIP (NCT02138825), a phase 2 study to evaluate efficacy and safety of riociguat (a soluble guanylate cyclase stimulator) in patients with $\mathrm{PH}$ associated with idiopathic interstitial pneumonias (including IPF), was terminated early, as patients receiving riociguat showed an increased risk of mortality and serious adverse events as compared to patients receiving placebo. It should also be recalled that the ARTEMIS-IPF trial showed that ambrisentan (an endothelin A receptor antagonist) was not deemed effective in treating IPF and may be associated with an increased risk for disease progression and respiratory hospitalizations (61). Further studies are needed to identify which subset of IPF patients may benefit from therapies targeting $\mathrm{PH}$. A phase $2 / 3$ trial evaluating the safety and efficacy of inhaled treprostinil in patients with $\mathrm{PH}$ associated with ILD is ongoing (NCT02630316).

\section{Novel therapies with negative recent phase 2/3 trials}

It is worthwhile to mention a few recent negative clinical trials, since they provide additional insights into IPF biology and guide future research.

\section{Anti-IL13 antibody}

Recently, Raghu et al. reported the results of a phase 2 randomized controlled trial (RCT) evaluating the efficacy and safety of SAR156597 (ESTAIR). SAR156507 is a monoclonal immunoglobulin G4 antibody designed to neutralize both IL-4 and IL-13 (62). The study was not successful in demonstrating a favorable effect on the primary endpoint (change in FVC over 52 weeks), nor in secondary outcome measures. The authors reported numerically fewer AEs in the SAR156597 arms, albeit AE events were few. This study should be considered together with other negative phase 2 RCTs targeting IL-13 with tralokinumab and lebrikizumab. In total, four RCTs were unsuccessful in demonstrating a benefit from employing monoclonal antibodies that block IL-13 in patients with IPF, thus it is unlikely that inhibiting the IL-13 pathway will have a future role in the treatment of IPF (63).

\section{Anti-CCL2 antibody}

A phase 2 randomized, double-blind placebo-controlled dose-ranging study testing safety and efficacy of carlumab (a humanized monoclonal antibody targeting CCL2) in patients with IPF failed to find a benefit from carlumab therapy (64). The study was terminated early due to a trend towards worsening of lung function in the carlumab 
treatment arms. The authors observed that even with carlumab therapy free CCL2 levels were increased above baseline over time, and speculated that this might be a reason why the carlumab therapy failed to provide a benefit in patients with IPF. However, a recent study by Milger et al. offered another biological explanation for the failure of the carlumab trial (65). They identified CCR2 expressing $\mathrm{CD}^{+} \mathrm{T}$ lymphocytes as a subset of $\mathrm{CD}^{+}$cells displaying anti-inflammatory and antifibrotic properties and explored their role in lung fibrosis. This study suggested that CCL2 might act on these $\mathrm{CCR} 2^{+} \mathrm{CD} 4^{+}$cells to abrogate inflammation and fibrosis, and that the therapeutic failure of carlumab might be related to suppression of this cell population.

\section{Anti-Lysyl oxidase-like 2 (LOXL2) antibody}

Lysyl oxidase (LOX) and LOX-like (LOXL) are enzymes involved in collagen cross-linking and are highly expressed in various fibrotic diseases $(66,67)$. Simtuzumab (monoclonal antibody against LOXL2) has been shown to prevent and reverse bleomycin-induced pulmonary fibrosis in mice (68). However, a phase 2 study in IPF (NCT01769196) did not suggest beneficial effects of simtuzumab on progressionfree survival (66). Targeting other LOX/LOXL family proteins and/or other cross-linking enzymes (e.g., transglutaminase 2) may also be important in IPF.

\section{$\mathrm{N}$-acetylcysteine (NAC)}

The 2015 IPF Guideline (1) recommended against NAC, based on the results of 3 RCTs including IFIGENIA (69). The pooled analysis of these three RCTs (69-72) suggested no significant benefit on mortality, FVC change, or quality of life using NAC monotherapy, although two out of the three studies $(69,70)$ reported a significant increase in $6 M W D$ using NAC monotherapy.

In a recent 24-week randomized, double-blind, placebocontrolled study (PANORAMA study), the combination of NAC and pirfenidone significantly increased the adjusted rate of FVC decline compared to placebo and pirfenidone (73). However, this result should be interpreted with caution, because the PANORAMA trial was designed to address the tolerability of the combination therapy as the primary endpoint and not designed to determine the efficacy of the combined treatment (74). Recent posthoc analysis of the NIH PANTHER trial (75) identified a subgroup of patients with the Tollip TT genotype that exhibited benefit from NAC therapy in a composite endpoint of disease progression, hospital admissions, and mortality, whereas the Tollip CC genotype performed poorer in this endpoint (76).

Overall, the therapeutic potential of NAC for patients with IPF remains undefined. Future (pharmacogenomics) trials may reveal a subgroup of patients more likely to benefit from NAC therapy than others (77). Others have entertained the concept that the use of inhaled NAC in patients with IPF could be considered (1).

\section{Novel therapies evaluated in phase 1 trials}

\section{Stem cells}

Over the past decade researchers have entertained the possibility of using stem cells for the treatment of IPF. A recent manuscript has reviewed the efficacy of mesenchymal stem cells (MSCs) in animal models of acute lung injury and fibrosis, and catalogued several possible mechanisms of action (78). However, to date it is not known whether stem cells will benefit patients with IPF. Moreover, concerns have been raised that there may be potential harm from stem cell treatments promoted by direct to consumer marketers $(79,80)$. To date peerreviewed IPF stem cell research is limited to a few small phase 1 safety trials employing MSCs (81) or alveolar type II cells (82) suggesting acceptable safety profiles. There are many variables and unanswered questions that need to be addressed regarding type and preparation of stem cells, as well as, how many and how often to infuse them and whether they impact upon disease progression. Thus, we do not currently recommend employing stem cells for the treatment of IPF outside of the conduct of well-designed randomized trials.

\section{Senolytics}

Senescent cells accumulate in IPF lung and may contribute to fibrogenesis through various mechanisms, including resistance to apoptosis and via a profibrotic senescent associated secretory prolife (83-86). Employment of drugs that remove senescent cells, termed senolytics, have been shown to block pulmonary fibrosis in animal and ex vivo models of pulmonary fibrosis $(86,87)$, and promote IPF fibroblast apoptosis (88). A recent open label trial involving 14 patients treated with senolytics, specifically dasatinib plus quercetin, for 3 weeks found that there was an interval increase in physical function as measured by $6 \mathrm{MWD}$, 4-meter gait speed, and chair-stands time (89). Although these results 
are intriguing, it is not clear whether the effects of the senolytics were due to an improvement in lung function or in other organs that are involved in exercise capacity, namely the heart and skeletal muscle. Thus, large randomized trials will be necessary to determine whether senolytics may serve as an effective therapy for the treatment of IPF.

\section{Nonpharmacological management}

Comprehensive treatment plans for IPF should also address several non-pharmacological management options that may affect quality of life. Smoking cessation, vaccines, pulmonary rehabilitation and supplemental oxygen are among these important non-pharmacological areas to be offered to patients.

\section{Pulmonary rehabilitation}

Pulmonary rehabilitation is an approach to improve the functional status of patients with chronic advanced lung disease through respiratory muscle and exercise training. A recent systematic review and meta-analysis indicated that pulmonary rehabilitation in IPF patients increases exercise tolerance and quality of life (90).

\section{Oxygen therapy}

Oxygen therapy in hypoxemic patients with IPF is strongly recommended by the clinical practice guidelines (91). This strong recommendation is influenced by physiological rationale rather than strong data regarding physiologic or QOL outcomes to support its use. Oxygen therapy also appears to improve exercise tolerance during exercise $(92,93)$.

\section{Depression}

Depression is common co-morbidity in patients with IPF and was reported to be as high as $49.2 \%$ in one study (94). While its impact on clinical outcome is not completely clear, we believe depression in IPF should be addressed and treated because of its impact on the quality of life $(95,96)$.

\section{Obstructive sleep apnea (OSA)}

OSA is common in patients with IPF. Untreated OSA affects sleep quality and may have a negative impact on the quality of life for patients with IPF. One study demonstrated that effective continuous positive airway pressure (CPAP) in IPF patients with moderate-to-severe OSA significantly improved the quality of their sleep and life 1 year after initiating CPAP (97).

\section{Lung transplant}

Lung transplant is addressed in other articles in this journal. Inasmuch as IPF may progress despite use of antifibrotic medications, lung transplantation is commonly considered for patients with moderate to severe disease (1). The International Society of Heart and Lung Transplantation (ISHLT) guideline for transplant referral and listing of patients with interstitial lung disease are not specific to those with IPF, and were published before the use of antifibrotic therapy was widespread (98). Introduction of disease-stabilizing antifibrotic therapy for IPF, twinned with advances in lung transplantation, mean that previously accepted age cutoffs for lung transplantation might no longer be appropriate. More data are required as this evidence will be important in guiding the timing of lung transplantation (99).

\section{Summary}

Over the past decade, the efforts of pharmaceutical companies, basic scientists and clinical researchers have resulted in significant strides using pharmacological and nonpharmacological therapy to treat patients afflicted with IPF. Novel agents and combination therapy are being tested currently, and the results of several recently published phase 2 clinical trials suggest that further additions to our pharmacologic armamentarium may soon be available. It is our bias that patients with IPF should be referred whenever possible to study sites so that together we can accelerate trial enrollment and approval of new and combination therapies for the treatment of IPF.

\section{Acknowledgments}

None.

\section{Footnote}

Conflicts of Interest: JA Lasky has participated in both advisory boards and FDA-approved educational activities for Genentech and Boehringer Ingelheim. The other authors have no conflicts of interest to declare. 


\section{References}

1. Raghu G, Rochwerg B, Zhang Y, et al. An Official ATS/ ERS/JRS/ALAT Clinical Practice Guideline: Treatment of Idiopathic Pulmonary Fibrosis. An Update of the 2011 Clinical Practice Guideline. Am J Respir Crit Care Med 2015;192:e3-19. Erratum in: Am J Respir Crit Care Med 2015;192:644. Dosage error in article text.

2. Taniguchi H, Ebina M, Kondoh Y, et al. Pirfenidone in idiopathic pulmonary fibrosis. Eur Respir J 2010;35:821-9.

3. Noble PW, Albera C, Bradford WZ, et al. Pirfenidone in patients with idiopathic pulmonary fibrosis (CAPACITY): two randomised trials. Lancet 2011;377:1760-9.

4. King TE, Bradford WZ, Castro-Bernardini S, et al. A phase 3 trial of pirfenidone in patients with idiopathic pulmonary fibrosis. N Engl J Med 2014;370:2083-92.

5. Richeldi L, du Bois RM, Raghu G, et al. Efficacy and safety of nintedanib in idiopathic pulmonary fibrosis. $\mathrm{N}$ Engl J Med 2014;370:2071-82.

6. Costabel U, Albera C, Lancaster LH, et al. An OpenLabel Study of the Long-Term Safety of Pirfenidone in Patients with Idiopathic Pulmonary Fibrosis (RECAP). Respiration 2017;94:408-15.

7. Crestani B, Huggins JT, Kaye M, et al. Long-term safety and tolerability of nintedanib in patients with idiopathic pulmonary fibrosis: results from the open-label extension study, INPULSIS-ON. Lancet Respir Med 2019;7:60-8.

8. Kolb M, Bonella F, Wollin L. Therapeutic targets in idiopathic pulmonary fibrosis. Respir Med 2017;131:49-57.

9. Cottin V, Koschel D, Günther A, et al. Long-term safety of pirfenidone: results of the prospective, observational PASSPORT study. ERJ Open Res 2018. doi: 10.1183/23120541.00084-2018.

10. Lancaster LH, de Andrade JA, Zibrak JD, et al. Pirfenidone safety and adverse event management in idiopathic pulmonary fibrosis. Eur Respir Rev 2017. doi: 10.1183/16000617.0057-2017.

11. Cottin V, Maher T. Long-term clinical and real-world experience with pirfenidone in the treatment of idiopathic pulmonary fibrosis. Eur Respir Rev 2015;24:58-64.

Erratum in: "Long-term clinical and real-world experience with pirfenidone in the treatment of idiopathic pulmonary fibrosis." Vincent Cottin and Toby Maher. Eur Respir Rev 2015;24:58-64. [Eur Respir Rev 2015].

12. Lederer DJ, Martinez FJ. Idiopathic Pulmonary Fibrosis. N Engl J Med 2018;379:797-8.

13. Corte T, Bonella F, Crestani B, et al. Safety, tolerability and appropriate use of nintedanib in idiopathic pulmonary fibrosis. Respir Res 2015;16:116.

14. Wollin L, Wex E, Pautsch A, et al. Mode of action of nintedanib in the treatment of idiopathic pulmonary fibrosis. Eur Respir J 2015;45:1434-45.

15. Nathan SD, Albera C, Bradford WZ, et al. Effect of pirfenidone on mortality: pooled analyses and metaanalyses of clinical trials in idiopathic pulmonary fibrosis. Lancet Respir Med 2017;5:33-41.

16. Richeldi L, Cottin V, du Bois RM, et al. Nintedanib in patients with idiopathic pulmonary fibrosis: Combined evidence from the TOMORROW and INPULSIS(®) trials. Respir Med 2016;113:74-9.

17. Ogura T, Taniguchi H, Azuma A, et al. Safety and pharmacokinetics of nintedanib and pirfenidone in idiopathic pulmonary fibrosis. Eur Respir J 2015;45:1382-92.

18. Vancheri C, Kreuter M, Richeldi L, et al. Nintedanib with Add-on Pirfenidone in Idiopathic Pulmonary Fibrosis. Results of the INJOURNEY Trial. Am J Respir Crit Care Med 2018;197:356-63.

19. Flaherty KR, Fell CD, Huggins JT, et al. Safety of nintedanib added to pirfenidone treatment for idiopathic pulmonary fibrosis. Eur Respir J 2018. doi: 10.1183/13993003.00230-2018. Erratum in: "Safety of nintedanib added to pirfenidone treatment for idiopathic pulmonary fibrosis." Kevin R. Flaherty, Charlene D. Fell, J. Terrill Huggins, Hilario Nunes, Robert Sussman, Claudia Valenzuela, Ute Petzinger, John L. Stauffer, Frank Gilberg, Monica Bengus and Marlies Wijsenbeek. Eur Respir J 2018;52:1800230. [Eur Respir J 2018].

20. Richeldi L, Fletcher S, Adamali H, et al. No relevant pharmacokinetic drug-drug interaction between nintedanib and pirfenidone. Eur Respir J 2019. doi: 10.1183/13993003.01060-2018.

21. Maher TM, van der Aar EM, Van de Steen O, et al. Safety, tolerability, pharmacokinetics, and pharmacodynamics of GLPG1690, a novel autotaxin inhibitor, to treat idiopathic pulmonary fibrosis (FLORA): a phase 2 a randomised placebo-controlled trial. Lancet Respir Med 2018;6:627-35.

22. Raghu G, van den Blink B, Hamblin MJ, et al. Effect of Recombinant Human Pentraxin 2 vs Placebo on Change in Forced Vital Capacity in Patients With Idiopathic Pulmonary Fibrosis: A Randomized Clinical Trial. JAMA 2018;319:2299-307.

23. Khalil N, Manganas H, Ryerson CJ, et al. Phase 2 clinical trial of PBI-4050 in patients with idiopathic pulmonary fibrosis. Eur Respir J 2019. doi: 10.1183/13993003.00663-2018.

24. Shea BS, Tager AM. Role of the lysophospholipid mediators lysophosphatidic acid and sphingosine 
1-phosphate in lung fibrosis. Proc Am Thorac Soc 2012;9:102-10.

25. Bain G, Shannon KE, Huang F, et al. Selective Inhibition of Autotaxin Is Efficacious in Mouse Models of Liver Fibrosis. J Pharmacol Exp Ther 2017;360:1-13.

26. Tager AM, LaCamera P, Shea BS, et al. The lysophosphatidic acid receptor LPA1 links pulmonary fibrosis to lung injury by mediating fibroblast recruitment and vascular leak. Nat Med 2008;14:45-54.

27. Castelino FV, Bain G, Pace VA, et al. An Autotaxin/ Lysophosphatidic Acid/Interleukin-6 Amplification Loop Drives Scleroderma Fibrosis. Arthritis Rheumatol 2016;68:2964-74.

28. Palmer SM, Snyder L, Todd JL, et al. Randomized, Double-Blind, Placebo-Controlled, Phase 2 Trial of BMS986020, a Lysophosphatidic Acid Receptor Antagonist for the Treatment of Idiopathic Pulmonary Fibrosis. Chest 2018;154:1061-9.

29. Lasky JA, Ortiz LA, Tonthat B, et al. Connective tissue growth factor mRNA expression is upregulated in bleomycin-induced lung fibrosis. Am J Physiol 1998;275:L365-71.

30. Yang J, Velikoff M, Canalis E, et al. Activated alveolar epithelial cells initiate fibrosis through autocrine and paracrine secretion of connective tissue growth factor. Am J Physiol Lung Cell Mol Physiol 2014;306:L786-96.

31. Raghu G, Scholand MB, de Andrade J, et al. FG3019 anti-connective tissue growth factor monoclonal antibody: results of an open-label clinical trial in idiopathic pulmonary fibrosis. Eur Respir J 2016;47:1481-91.

32. Clukers J, Lanclus M, Mignot B, et al. Quantitative CT analysis using functional imaging is superior in describing disease progression in idiopathic pulmonary fibrosis compared to forced vital capacity. Respir Res 2018;19:213.

33. Murray LA, Rosada R, Moreira AP, et al. Serum amyloid $\mathrm{P}$ therapeutically attenuates murine bleomycin-induced pulmonary fibrosis via its effects on macrophages. PLoS One 2010;5:e9683.

34. Pilling D, Gomer RH. The Development of Serum Amyloid P as a Possible Therapeutic. Front Immunol 2018;9:2328.

35. Gagnon L, Leduc M, Thibodeau JF, et al. A Newly Discovered Antifibrotic Pathway Regulated by Two Fatty Acid Receptors: GPR40 and GPR84. Am J Pathol 2018;188:1132-48.

36. Munger JS, Huang X, Kawakatsu H, et al. The integrin alpha $\mathrm{v}$ beta 6 binds and activates latent TGF beta 1: a mechanism for regulating pulmonary inflammation and fibrosis. Cell 1999;96:319-28.

37. Chen H, Qu J, Huang X, et al. Mechanosensing by the a6-integrin confers an invasive fibroblast phenotype and mediates lung fibrosis. Nat Commun 2016;7:12564.

38. Mackinnon AC, Gibbons MA, Farnworth SL, et al. Regulation of transforming growth factor- $\beta 1$-driven lung fibrosis by galectin-3. Am J Respir Crit Care Med 2012;185:537-46.

39. Smaldone GC. Repurposing of gamma interferon via inhalation delivery. Adv Drug Deliv Rev 2018;133:87-92.

40. King TE, Albera C, Bradford WZ, et al. Effect of interferon gamma-1b on survival in patients with idiopathic pulmonary fibrosis (INSPIRE): a multicentre, randomised, placebo-controlled trial. Lancet 2009;374:222-8.

41. Jaffe HA, Buhl R, Mastrangeli A, et al. Organ specific cytokine therapy. Local activation of mononuclear phagocytes by delivery of an aerosol of recombinant interferon-gamma to the human lung. J Clin Invest 1991;88:297-302.

42. Diaz KT, Skaria S, Harris K, et al. Delivery and safety of inhaled interferon- $\gamma$ in idiopathic pulmonary fibrosis. J Aerosol Med Pulm Drug Deliv 2012;25:79-87.

43. Skaria SD, Yang J, Condos R, et al. Inhaled Interferon and Diffusion Capacity in Idiopathic Pulmonary Fibrosis (IPF). Sarcoidosis Vasc Diffuse Lung Dis 2015;32:37-42.

44. Donahoe M, Valentine VG, Chien N, et al. AutoantibodyTargeted Treatments for Acute Exacerbations of Idiopathic Pulmonary Fibrosis. PLoS One 2015;10:e0127771.

45. Raghu G, Freudenberger TD, Yang S, et al. High prevalence of abnormal acid gastro-oesophageal reflux in idiopathic pulmonary fibrosis. Eur Respir J 2006;27:136-42.

46. Lee JS, Ryu JH, Elicker BM, et al. Gastroesophageal reflux therapy is associated with longer survival in patients with idiopathic pulmonary fibrosis. Am J Respir Crit Care Med 2011;184:1390-4.

47. Lee JS, Collard HR, Anstrom KJ, et al. Anti-acid treatment and disease progression in idiopathic pulmonary fibrosis: an analysis of data from three randomised controlled trials. Lancet Respir Med 2013;1:369-76.

48. Kreuter M, Wuyts W, Renzoni E, et al. Antacid therapy and disease outcomes in idiopathic pulmonary fibrosis: a pooled analysis. Lancet Respir Med 2016;4:381-9.

49. Kreuter M, Spagnolo P, Wuyts W, et al. Antacid Therapy and Disease Progression in Patients with Idiopathic Pulmonary Fibrosis Who Received Pirfenidone. Respiration 2017;93:415-23.

50. Raghu G, Pellegrini CA, Yow E, et al. Laparoscopic antireflux surgery for the treatment of idiopathic pulmonary 
fibrosis (WRAP-IPF): a multicentre, randomised, controlled phase 2 trial. Lancet Respir Med 2018;6:707-14.

51. Fidler L, Sitzer N, Shapera S, et al. Treatment of Gastroesophageal Reflux in Patients With Idiopathic Pulmonary Fibrosis: A Systematic Review and MetaAnalysis. Chest 2018;153:1405-15.

52. Tran T, Suissa S. The effect of anti-acid therapy on survival in idiopathic pulmonary fibrosis: a methodological review of observational studies. Eur Respir J 2018. doi: 10.1183/13993003.00376-2018.

53. Bédard Méthot D, Leblanc É, Lacasse Y. Meta-analysis of Gastroesophageal Reflux Disease and Idiopathic Pulmonary Fibrosis. Chest 2019;155:33-43.

54. Hewitt RJ, Molyneaux PL. The respiratory microbiome in idiopathic pulmonary fibrosis. Ann Transl Med 2017;5:250.

55. Shulgina L, Cahn AP, Chilvers ER, et al. Treating idiopathic pulmonary fibrosis with the addition of cotrimoxazole: a randomised controlled trial. Thorax 2013;68:155-62.

56. Brownell R, Kaminski N, Woodruff PG, et al. Precision Medicine: The New Frontier in Idiopathic Pulmonary Fibrosis. Am J Respir Crit Care Med 2016;193:1213-8.

57. Kolb M, Raghu G, Wells AU, et al. Nintedanib plus Sildenafil in Patients with Idiopathic Pulmonary Fibrosis. N Engl J Med 2018;379:1722-31.

58. Zisman DA, Schwarz M, Anstrom KJ, et al. A controlled trial of sildenafil in advanced idiopathic pulmonary fibrosis. N Engl J Med 2010;363:620-8.

59. Han MK, Bach DS, Hagan PG, et al. Sildenafil preserves exercise capacity in patients with idiopathic pulmonary fibrosis and right-sided ventricular dysfunction. Chest 2013;143:1699-708.

60. Behr J, Nathan SD, Harari S, et al. Sildenafil added to pirfenidone in patients with advanced idiopathic pulmonary fibrosis and risk of pulmonary hypertension: A Phase IIb, randomised, double-blind, placebocontrolled study - Rationale and study design. Respir Med 2018;138:13-20.

61. Raghu G, Behr J, Brown KK, et al. Treatment of idiopathic pulmonary fibrosis with ambrisentan: a parallel, randomized trial. Ann Intern Med 2013;158:641-9.

62. Raghu G, Richeldi L, Crestani B, et al. SAR156597 in idiopathic pulmonary fibrosis: a phase 2 placebocontrolled study (DRI11772). Eur Respir J 2018. doi: 10.1183/13993003.01130-2018.

63. Wijsenbeek MS, Kool M, Cottin V. Targeting interleukin-13 in idiopathic pulmonary fibrosis: from promising path to dead end. Eur Respir J 2018. doi:
10.1183/13993003.02111-2018.

64. Raghu G, Martinez FJ, Brown KK, et al. CC-chemokine ligand 2 inhibition in idiopathic pulmonary fibrosis: a phase 2 trial of carlumab. Eur Respir J 2015;46:1740-50.

65. Milger K, Yu YY, Brudy E, et al. Pulmonary CCR2(+) CD4(+) $\mathrm{T}$ cells are immune regulatory and attenuate lung fibrosis development. Thorax 2017;72:1007-20.

66. Raghu G, Brown KK, Collard HR, et al. Efficacy of simtuzumab versus placebo in patients with idiopathic pulmonary fibrosis: a randomised, double-blind, controlled, phase 2 trial. Lancet Respir Med 2017;5:22-32.

67. Chen L, Li S, Li W. LOX/LOXL in pulmonary fibrosis: potential therapeutic targets. J Drug Target 2019;27:790-6.

68. Barry-Hamilton V, Spangler R, Marshall D, et al. Allosteric inhibition of lysyl oxidase-like-2 impedes the development of a pathologic microenvironment. Nat Med 2010;16:1009-17.

69. Martinez FJ, de Andrade JA, Anstrom KJ, et al. Randomized trial of acetylcysteine in idiopathic pulmonary fibrosis. N Engl J Med 2014;370:2093-101.

70. Tomioka H, Kuwata Y, Imanaka K, et al. A pilot study of aerosolized $\mathrm{N}$-acetylcysteine for idiopathic pulmonary fibrosis. Respirology 2005;10:449-55.

71. Homma S, Azuma A, Taniguchi H, et al. Efficacy of inhaled $\mathrm{N}$-acetylcysteine monotherapy in patients with early stage idiopathic pulmonary fibrosis. Respirology 2012;17:467-77.

72. Demedts M, Behr J, Buhl R, et al. High-dose acetylcysteine in idiopathic pulmonary fibrosis. N Engl J Med 2005;353:2229-42.

73. Behr J, Bendstrup E, Crestani B, et al. Safety and tolerability of acetylcysteine and pirfenidone combination therapy in idiopathic pulmonary fibrosis: a randomised, double-blind, placebo-controlled, phase 2 trial. Lancet Respir Med 2016;4:445-53.

74. Raghu G, Noth I, Martinez F. N-acetylcysteine for idiopathic pulmonary fibrosis: the door is still open. Lancet Respir Med 2017;5:e1-e2.

75. Raghu G, Anstrom KJ, King TE, et al. Prednisone, azathioprine, and $\mathrm{N}$-acetylcysteine for pulmonary fibrosis. N Engl J Med 2012;366:1968-77.

76. Oldham JM, Ma SF, Martinez FJ, et al. TOLLIP, MUC5B, and the Response to N-Acetylcysteine among Individuals with Idiopathic Pulmonary Fibrosis. Am J Respir Crit Care Med 2015;192:1475-82.

77. Fois AG, Paliogiannis $\mathrm{P}$, Sotgia S, et al. Evaluation of oxidative stress biomarkers in idiopathic pulmonary 
fibrosis and therapeutic applications: a systematic review. Respir Res 2018;19:51.

78. Li X, Yue S, Luo Z. Mesenchymal stem cells in idiopathic pulmonary fibrosis. Oncotarget 2017;8:102600-16.

79. Knoepfler PS, Turner LG. The FDA and the US directto-consumer marketplace for stem cell interventions: a temporal analysis. Regen Med 2018;13:19-27.

80. Sipp D, Robey PG, Turner L. Clear up this stem-cell mess. Nature 2018;561:455-7.

81. Glassberg MK, Minkiewicz J, Toonkel RL, et al. Allogeneic Human Mesenchymal Stem Cells in Patients With Idiopathic Pulmonary Fibrosis via Intravenous Delivery (AETHER): A Phase I Safety Clinical Trial. Chest 2017;151:971-81.

82. Serrano-Mollar A, Gay-Jordi G, Guillamat-Prats R, et al. Safety and Tolerability of Alveolar Type II Cell Transplantation in Idiopathic Pulmonary Fibrosis. Chest 2016;150:533-43.

83. Kirkland JL, Tchkonia T, Zhu Y, et al. The Clinical Potential of Senolytic Drugs. J Am Geriatr Soc 2017;65:2297-301.

84. Mora AL, Rojas M, Pardo A, et al. Emerging therapies for idiopathic pulmonary fibrosis, a progressive age-related disease. Nat Rev Drug Discov 2017;16:810.

85. Alsafadi HN, Staab-Weijnitz CA, Lehmann M, et al. An ex vivo model to induce early fibrosis-like changes in human precision-cut lung slices. Am J Physiol Lung Cell Mol Physiol 2017;312:L896-L902.

86. Schafer MJ, White TA, Iijima K, et al. Cellular senescence mediates fibrotic pulmonary disease. Nat Commun 2017;8:14532.

87. Lehmann M, Korfei M, Mutze K, et al. Senolytic drugs target alveolar epithelial cell function and attenuate experimental lung fibrosis. Eur Respir J 2017. doi: 10.1183/13993003.02367-2016.

88. Hohmann MS, Habiel DM, Coelho AL, et al. Quercetin Enhances Ligand-induced Apoptosis in Senescent Idiopathic Pulmonary Fibrosis Fibroblasts and Reduces Lung Fibrosis In Vivo. Am J Respir Cell Mol Biol 2019;60:28-40.

89. Justice JN, Nambiar AM, Tchkonia T, et al. Senolytics in idiopathic pulmonary fibrosis: Results from a first-

Cite this article as: Saito S, Alkhatib A, Kolls JK, Kondoh Y, Lasky JA. Pharmacotherapy and adjunctive treatment for idiopathic pulmonary fibrosis (IPF). J Thorac Dis 2019;11(Suppl 14):S1740-S1754. doi: 10.21037/jtd.2019.04.62 in-human, open-label, pilot study. EBioMedicine 2019;40:554-63.

90. Gomes-Neto M, Silva CM, Ezequiel D, et al. Impact of Pulmonary Rehabilitation on Exercise Tolerance and Quality of Life in Patients With Idiopathic Pulmonary Fibrosis: A SYSTEMATIC REVIEW AND METAANALYSIS. J Cardiopulm Rehabil Prev 2018;38:273-8.

91. Raghu G, Collard HR, Egan JJ, et al. An official ATS/ ERS/JRS/ALAT statement: idiopathic pulmonary fibrosis: evidence-based guidelines for diagnosis and management. Am J Respir Crit Care Med 2011;183:788-824.

92. Dowman LM, McDonald CF, Bozinovski S, et al. Greater endurance capacity and improved dyspnoea with acute oxygen supplementation in idiopathic pulmonary fibrosis patients without resting hypoxaemia. Respirology 2017;22:957-64.

93. Visca D, Mori L, Tsipouri V, et al. Effect of ambulatory oxygen on quality of life for patients with fibrotic lung disease (AmbOx): a prospective, open-label, mixedmethod, crossover randomised controlled trial. Lancet Respir Med 2018;6:759-70.

94. Akhtar AA, Ali MA, Smith RP. Depression in patients with idiopathic pulmonary fibrosis. Chron Respir Dis 2013;10:127-33.

95. Lee YJ, Choi SM, Cho YJ, et al. Clinical impact of depression and anxiety in patients with idiopathic pulmonary fibrosis. PLoS One 2017;12:e0184300.

96. Matsuda T, Taniguchi H, Ando M, et al. Depression Is Significantly Associated with the Health Status in Patients with Idiopathic Pulmonary Fibrosis. Intern Med 2017;56:1637-44.

97. Mermigkis C, Bouloukaki I, Antoniou K, et al. Obstructive sleep apnea should be treated in patients with idiopathic pulmonary fibrosis. Sleep Breath 2015;19:385-91.

98. Weill D, Benden C, Corris PA, et al. A consensus document for the selection of lung transplant candidates: 2014--an update from the Pulmonary Transplantation Council of the International Society for Heart and Lung Transplantation. J Heart Lung Transplant 2015;34:1-15.

99. George PM, Patterson CM, Reed AK, et al. Lung transplantation for idiopathic pulmonary fibrosis. Lancet Respir Med 2019;7:271-82. 